\title{
An Overview of Corrosion Risk of Metal Culverts in Arkansas
}

\author{
Mdariful Hasan ${ }^{1}$ and Zahid Hossain ${ }^{2, *}$ \\ ${ }^{1}$ Department of Civil Engineering, Arkansas State University, Jonesboro, AR 72467 \\ ${ }^{2}$ Department of Civil Engineering, Arkansas State University, PO Box 1740, State University, AR 72467
}

\begin{abstract}
Metal culverts or pipes used in cross-drains along or across the Arkansas highway system are susceptible to corrode over time. Catastrophic incidents such as a complete washout of metal culverts along with roadway can be prevented if proper metals can be selected during the construction project. At present, the Arkansas Department of Transportation (ArDOT) does not have enough information about corrosion effects on metal culverts. The main objective of this study is to develop a user-friendly corrosion map for Arkansas by analyzing soil properties, water properties, and environmental data collected from the public domain as well as those gathered from laboratory experiments. Experimental data will be used to develop mathematical models to predict the resistivity and corrosive nature of soils. In this paper, relevant literature has been reviewed to narrow down the specific gaps in the available data and limitations in using methods to analyze the risk, challenges in developing regression and neural network models and risk mapping. Findings of this study have helped the research team to design the experimental plan and appropriate metrics need to be considered for developing the predictive models for this study.
\end{abstract}

\section{Introduction}

Highways of Arkansas are susceptible to corrosion in metal cross-drains. Usually, corrugated steel pipes, coated or uncoated aluminum pipe and reinforced concrete pipes are used as cross-drains materials. The corrosion rate of the pipe or culvert materials depends on material properties itself, soil properties, and environmental factors. For example, corrosiveness of soil, quality of water passing through the drains, quality of sediments carried by water, quality of groundwater, depth of groundwater, and properties of backfill material, can significantly impact the corrosion rates. Several studies have been conducted in different states to analyze the service life of metal culverts, or pipes and to map the risk of corrosion. However, ArDOT does not have any scientific information about the spatial distribution of corrosion rates in Arkansas. Specific guidelines related to metal pipe material selection and their installation and/or replacement schedule are also not available. The main objective of this study is to develop a user-friendly corrosion map, which will indicate the vulnerable zones for prospective corrosion in Arkansas. In addition, detailed guidelines for selecting appropriate materials along with their replacement/installation will also be developed. In this paper, a detail literature review is presented along with a research plan to discuss the governing factors and their relative importance in corrosion risk analysis.

\section{Literature review}

\footnotetext{
* Corresponding author: mhossain $@$ astate.edu
}

Usually reinforced concrete, steel, aluminum, and plastics are used as culvert and pipe materials. Most of the transportation agencies have a qualified product list for culvert and pipe materials, which are usually listed based on the established American Society for Testing and Materials (ASTM) and American Association of State Highway and Transportation Officials (AASHTO) standards. However, the corrosion potential of these materials in the field varies unpredictably because of the wider variability of soil and water properties related to corrosion protection. Electrical resistivity (ER) and $\mathrm{pH}$ are primarily considered as two major indicators of corrosivity of these materials. In general, the ER of surface water is higher than $5000 \mathrm{ohm} . \mathrm{cm}$, and seawater is around $25 \mathrm{ohm} . \mathrm{cm}$. For rock, the ER is usually greater than 50,000 ohm.cm; for sand, ER varies from 30,000 ohm.cm to 50,000 ohm.cm; for gravel, ER varies from $10,000 \mathrm{ohm} . \mathrm{cm}$ to $30,000 \mathrm{ohm} . \mathrm{cm}$; for loam, ER varies from 2,000 ohm.cm to $10,000 \mathrm{ohm} . \mathrm{cm}$; and for clay, ER varies from 2,000 ohm.cm to $750 \mathrm{ohm} . \mathrm{cm}$ [1]. To protect the culvert or pipe materials from corrosion, different types of coatings and cathodic protection, are suggested in different kinds of literature based on the analyses of $\mathrm{pH}$ and ER.

\subsection{Factor affects corrosion rate}

The rate of corrosion varies around over the regions, and it depends on various associated material properties, soil physical and chemical properties, and environmental conditions. According to the National Cooperative Highway Research Program (NCHRP), different types of 
corrosion can occur in highway culvert's metallic environment, but galvanic corrosion, crevice corrosion, pitting, erosion corrosion, stress corrosion, and biological corrosion are the major ones, which can occur in presence of soil and water with metal [1]. These authors summarized the major driving forces for corrosion as temperature, the chemical composition of surrounding media, $\mathrm{pH}$, the presence of $\mathrm{H}_{2} \mathrm{~S}$, chloride ion, gravitational, or pellicular water. However, the $\mathrm{pH}$ and resistivity of soil and water are found to be common and correlated with the durability of metal pipes. These researchers also reported that the soil-side corrosion controls the service life of culverts when $\mathrm{pH}$ is greater than 7.3, and water-side corrosion plays a major role in the overall corrosion when abrasive bed loads are presents. Ismail et al. [2] analyzed the impacts of moisture content, $\mathrm{pH}$, resistivity, redox potential on the corrosivity, and these researchers showed a strong correlation between corrosion rate and $\mathrm{pH}$, resistivity and redox potential. For lower $\mathrm{pH}$, redox potential and resistivity values the corrosivity is high. Norhazilan et al. [3] studied the impacts of geotechnical properties like clay content, plasticity index on the corrosion rates. These researchers found that increases in clay content and plasticity index trigger the corrosion potentials. Ferreira et al. [4] investigated the impact of chemical composition on corrosion potential of soils.

Several researchers have worked or are still working on corrosion potential of backfill materials. For example, Elias et al. [5], Thapalia [6], Brady [7] Tucker-Kulesza et al. [8], and Crowder [9] have studied different aspects of metal pipes and properties (geochemical and geophysical) of backfill materials for corrosion potential assessment. However, in practice, all the properties are not considered during corrosion rate prediction modeling or during corrosion risk analysis. For imported bedding and backfill material usage, the ArDOT has standard specifications about the gradation and compaction requirements. However, no studies have been carried out to determine the corrosion properties of backfill materials.

\subsection{Corrosion mapping methods}

Several approaches are available in the literature to quantify the remaining service life of metal culverts. However, three different approaches have been found in the literature for addressing corrosion risk mapping of an area. For mapping corrosion risk potential for concrete, National Resource Conservation Services (NRCS) uses the US Soil Survey Geographic (SSURGO) database and calibrate the risk attribute based on the soil texture and reaction, $\mathrm{Na}$ and $\mathrm{Mg}$ sulfate contents, and $\mathrm{NaCl}$ (NRCS 2018). The NRCS categorized the risk features into three categories: Low, Moderate, and High. According to the guideline, in general, sandy and organic soils with $\mathrm{pH}$ greater than 6.5 or fine-textured soils with $\mathrm{pH}$ greater than 6.0 with $\mathrm{Na}$ and or $\mathrm{Mg}$ sulfate content less than $1000 \mathrm{ppm}$, and $\mathrm{NaCl}$ content less than $2000 \mathrm{ppm}$ are considered as the "Low" risk category. Similarly, sandy and organic soils with $\mathrm{pH}$ ranging from 5.5 to 6.5 or fine-textured soils with $\mathrm{pH}$ ranging from 5.0 to 6.0 with $\mathrm{Na}$ and or $\mathrm{Mg}$ sulfate content ranging within $1000 \mathrm{ppm}$ to $7000 \mathrm{ppm}$, and $\mathrm{NaCl}$ content ranging from $2000 \mathrm{ppm}$ to $10000 \mathrm{ppm}$ is considered as the "Moderate" risk category. And, sandy and organic soils with $\mathrm{pH}$ less than 5.5 or fine-textured soils with $\mathrm{pH}$ less than 5.0 with $\mathrm{Na}$ and or $\mathrm{Mg}$ sulfate content greater than $7000 \mathrm{ppm}$, and $\mathrm{NaCl}$ content more than $10000 \mathrm{ppm}$ is considered as the "High" risk category. Figure 1 (a) shows an example of concrete corrosion risk map of Crittenden county of Arkansas based on the existing approaches followed by the NRCS and the United States Department of Agriculture (USDA) [10-12].

For uncoated steel, NRCS uses the SSURGO database and categorized the risk potentials in three similar ways. However, for uncoated steel, specifically, drainage class and texture of soils, the total acidity of the soil, soil resistivity at saturation, and conductivity of saturated extract are considered. Category "Low" is defined when the soil is well drained, in general, with coarse-textured soils, in combination with a total acidity less than $8 \mathrm{meq} / 100 \mathrm{~g}$, the resistivity at saturation is greater than or equal to $5000 \mathrm{ohms} / \mathrm{cm}$, and conductivity of saturated extract less than $0.3 \mathrm{mmhos} \mathrm{cm}^{-1}$. Category "Moderate" is defined when the soil is moderately well drained, in general, with moderately coarse-textured soils, in combination with total acidity ranges between 8 $\mathrm{meq} / 100 \mathrm{~g}$ to $12 \mathrm{meq} / 100 \mathrm{~g}$, resistivity at saturation lies within $2000 \mathrm{ohms} / \mathrm{cm}$ to $5000 \mathrm{ohms} / \mathrm{cm}$, and conductivity of saturated extract lies within $0.3 \mathrm{mmhos}$ $\mathrm{cm}^{-1}$ to $0.8 \mathrm{mmhos} \mathrm{cm}^{-1}$. And, "High" risk of corrosion potential is considered for fine-textured soils with varied draining conditions, along with total acidity greater than or equal to $12 \mathrm{meq} / 100 \mathrm{~g}$, resistivity at saturation is less than $2000 \mathrm{ohms} / \mathrm{cm}$, and conductivity of saturated

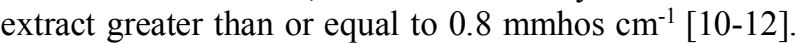
Figure 1 (b) shows a steel (uncoated) corrosion risk map of Crittenden county of Arkansas based on the existing approaches followed by USDA [10-12].

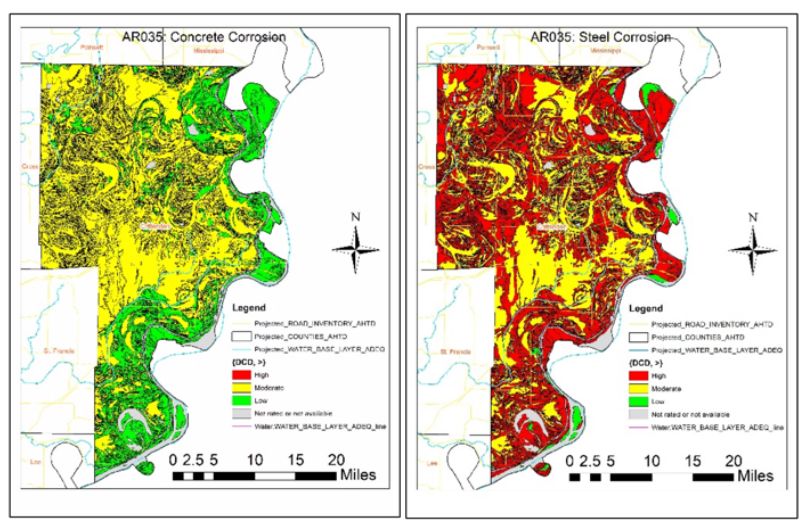

Fig. 1. Existing approaches to corrosion risk mapping. (left) concrete corrosion risk [10], and (right) uncoated steel corrosion risk [11].

Louisiana DOT has developed metal corrosion risk zone maps for the coastal parts of the state of Louisiana [13]. These researchers categorized corrosion potentials as "Mildly Corrosive," "Corrosive," "Highly Corrosive," 
and "Extremely Corrosive" based on the expected average life of metal pipes. A weighted doubly $25 \times 12$ matrix was used to categorize the risk potentials based on $\mathrm{pH}$ and resistivity of soil [13]. These corrosion risk metrics were categorized based on guidelines of the NCHRP synthesis 474 titled "Service Life of Culverts A Synthesis of Highway Practice" [1]. While determining the final lifespan of culverts, the Louisiana study followed the study of the Colorado Department of Transportation [14]. However, these studies did not combine all possible related soil parameters used by geotechnical engineers. Thus, a combined index or an agglomerated model is still required to categorize risk potential based on the routine engineering properties of site soils and other information available in the secondary literature.

\section{Research plan}

The corrosion rate assessment and risk analysis require significant data. The type of data also has different forms. The process of combining the data is critical in nature and requires effort. In a combination of primary (i.e., experimental data) and secondary sources of data are targeted to be used for the model development. The ArDOT has an extensive database of enriched geotechnical reports from previous projects in Arkansas. The United States Geological Survey (USGS) data related to water and sediment qualities are also targeted to be used in this project. The Arkansas Department of Environmental Quality (ADEQ) also has an extensive database of water quality parameters from different monitoring stations. Furthermore, the USDA has a database of extensive soil property data from their soil survey. Environmental and climatic data will also be collected from other sources. These data are planned to be used for the developing the models.

For the primary data from the field, soil sampling will be done from different parts of the state and laboratory investigation will be done on the collected soil samples based on the ASTM, AASHTO standards and other highway agency standards. For example, an NCHRP Report titled Corrosion in the soil environment: Soil resistivity and $\mathrm{pH}$ measurements established correlations between existing soil resistivity and soil $\mathrm{pH}$ testing methods including improved measurement techniques [15]. These suggested techniques will be cautiously applied in the current research. Finally, an extensive data association analysis will be done on the acquired datasets. A neuro-fuzzy approach will be followed to accommodate different types of variables in the model. Finally, based on the developed model, the corrosion risk will be assessed for any given condition and location in Arkansas. For mapping purposes, the ArcGIS tool will be used. In the mapping process, interpolation techniques such as Empirical Bayesian Kriging (EBK) and Inverse Distance Weighted (IDW) will be applied. Field observation results will be used to validate the interpolation methods. A detailed flowchart for implementing the research plan is presented in Figure 2.

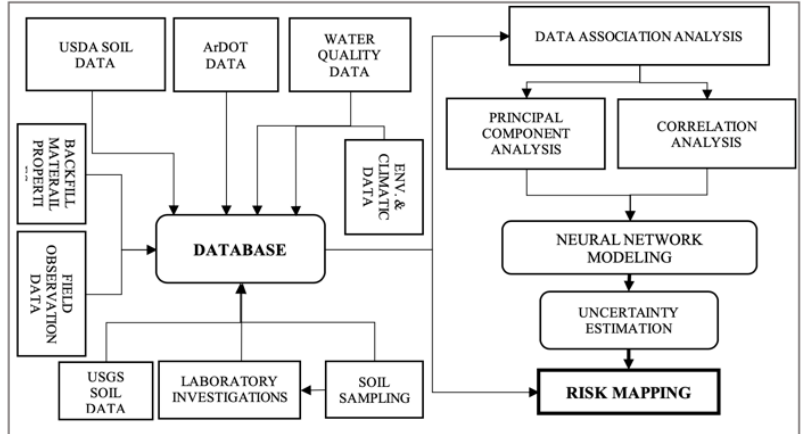

Fig. 2. Flowchart of the study methodology.

\subsection{Soil Sampling}

As part of the current study, twelve soil samples have been collected from different parts of ArDOT District 10 (see Figure 3). Locations of the collected soil samples are marked with star symbols in the map in Figure 4.

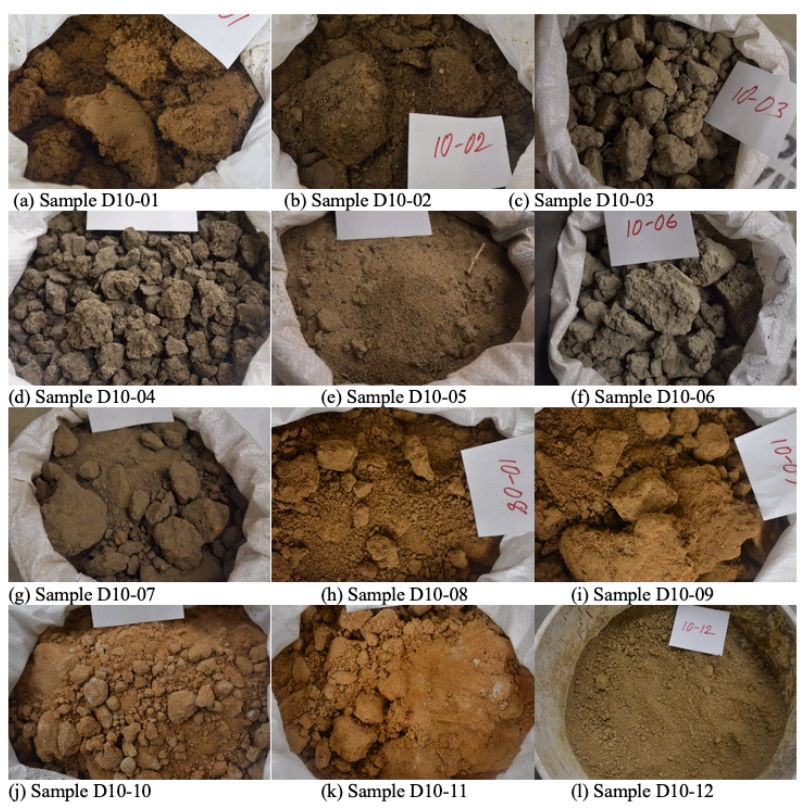

Fig. 3. Soil samples collected from different locations of District 10

\section{Findings}

A recent study by Elsayed [16] recommended that the AASHTO soil specific models are important for effective usage by practitioners. In general, in Arkansas, A-2-4, A-4 and A-6 type soils, classified according to the AASHTO classification system, are dominant. The ArDOT District 10 lies in the north-east corner of the state. For this study, District 10 is considered as the initial area of interest. A detailed soil classification map (Figure 4) for the district is prepared based on the USDA's soil survey information. The predominant soils types for this district are A-1-b, A-2, A-4, A-6, A-7-5, and A-7-6. The liquid limit can be up to 95 . And, the plasticity index varies from NP to 55 . 


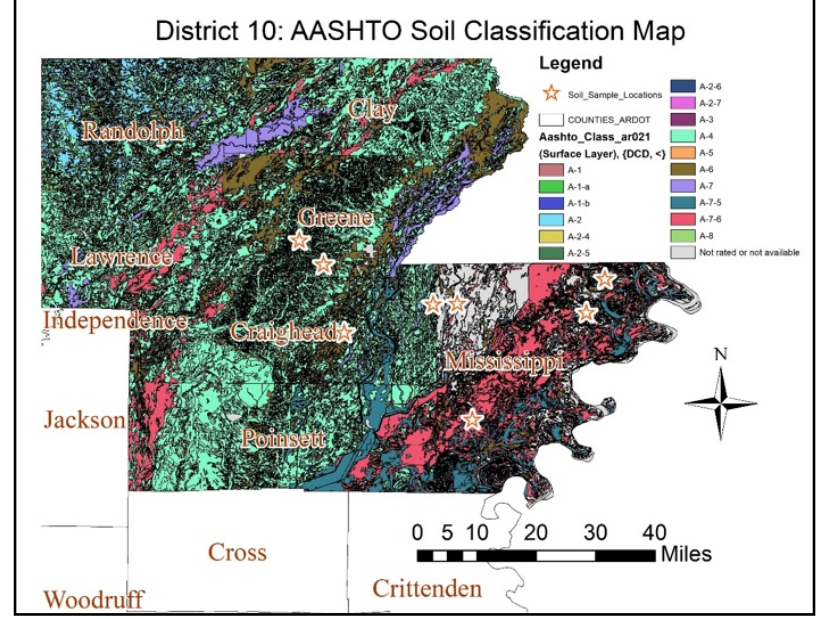

Fig. 4. Soil classification map and soil sampling locations [10, $11]$.

\section{Discussions}

This study will consider different types of real-time factors. A neural network model for corrosion prediction will be developed first and then considering associated uncertainty estimation, region-specific and soil classification specific risk will be determined. Finally, a corrosion risk map will be developed using ArcGIS. In addition, this study will investigate the maintenance perspective of cross-drains through life cycle cost analysis, which will help ArDOT to prevent additional investment by taking precautionary measures. It is expected that the findings of this study will help the department in robust decision making during the initial planning of new construction and during the costly repairs.

The authors would like to acknowledge the financial support from the Transportation Consortium of South-Central States (Tran-SET). The authors also want to acknowledge the cooperation of ArDOT District 10 Engineers - specifically, Brad Smithee, Alan Walter, Aaron Vowell, William Reddell, and Shannon Luke for cooperation in this research.

\section{References}

1. Maher, M., Hebeler, G., and Fuggle, A. (2015). Service Life of Culverts - A Synthesis of Highway Practice, Synthesis 474, Transportation Research Board, National Cooperative Highway Research Program, Washington, D.C.

2. Ismail, A.I.M., \& El-Shamy, A.M. (2009). Engineering behaviour of soil materials on the corrosion of mild steel. Applied clay science, 42(34), 356-362.

3. Norhazilan, M.N., Nordin, Y., Lim, K.S., Siti, R.O., Safuan, A.R.A., \& Norhamimi, M.H. (2012). Relationship between soil properties and corrosion of carbon steel. Journal of Applied Sciences Research, 8(3), 1739-1747.

4. Ferreira, C.A.M., Ponciano, J.A., Vaitsman, D.S., \& Pérez, D.V. (2007). Evaluation of the corrosivity of the soil through its chemical composition. Science of the total environment, 388(1-3), 250-255.

5. Elias, V., Fishman, K.L., Christopher, B.R., and Berg, R.R. (2009). Corrosion/degradation of soil reinforcements for mechanically stabilized earth walls and reinforced soil slopes. Federal Highway Administration (FHWA), Washington, D.C.

6. Thapalia, A. (2014). Geochemical studies of backfill aggregates, lake sediment cores and the hueco bolson aquifer. The University of Texas at El Paso, El Paso, Texas.

7. Brady, Z. (2016). Testing Aggregate Backfill for Corrosion Potential, Kansas Department of Transportation (KDOT), Topeka, KS.

8. Tucker-Kulesza, S., Snapp, M., \& Koehn, W. (2016). Electrical resistivity measurement of mechanically stabilized Earth wall backfill, (No. KTRAN: KSU-15-6). Kansas Department of Transportation, Topeka, KS.

9. Crowder, A. (2018). Field and Laboratory Characterization of Corrosion Potential in Highway Corrugated Metal Pipe, Kansas Department of Transportation, Topeka, KS.

10. Natural Resources Conservation Service (NRCS). (2018a). United States Department of Agriculture. Soil Survey Geographic (SSURGO) Database for [Crittenden, Arkansas]. Available online. Accessed [06/21/2018].

11. Natural Resources Conservation Service (NRCS). (2018b). United States Department of Agriculture. Web Soil Survey. Available online at https://websoilsurvey.nrcs.usda.gov/. Accessed [06/21/2018].

12. U.S. Department of Agriculture (USDA), National soil survey handbook, title 430-VI. http://www.nrcs.usda.gov/wps/portal/nrcs/detail/soil $\mathrm{s} / \mathrm{ref} /$ ?cid $=$ nrcs142p2_054242 Accessed [06/21/2018].

13. Tewari, S., and Manning, F. (2018). Spatial Delineation of Corrosion Zones for Metal Culverts Based on Coastal Louisiana Soil Characteristics. Transportation Research Board (No. 18-03467). Washington D.C.

14. Molinas, A., and Mommandi, A. (2009). Development of New Corrosion/Abrasion Guidelines for Selection of Culvert Pipe Materials. CDOT-2009-11. Colorado Dept. of Transportation, Research Branch, Denver, CO.

15. Vilda III, W.S., Lindemuth, D., Ellor, J.A., Islam, M., Ault, J.P., Flounders Jr, E.C., \& Repp, J. (2009). Corrosion in the soil environment: Soil resistivity and $\mathrm{pH}$ measurements, Corrpro Companies, Inc. National Cooperative Highway Research Program (NCHRP), Washington D.C.

16. Elsayed, A. (2016). Developing Embankment and Subgrade Stabilization Regional Specifications, (TRC -1308). Arkansas State Highway and Transportation Department, Little Rock, AR. 